\title{
Investigating a Possible Link between MRI Findings of Lumbar Disc Degeneration and Modic Changes in the Patients with Chronic Low Back Pain
}

\author{
Zahra Hasani ${ }^{1}$, Yasamin Davoudi ${ }^{2}$, Mohammad Hassani ${ }^{1}$, Emadzadeh Maryam ${ }^{3}$, Pedram Borhani ${ }^{1}$, Amirhosein \\ Kasaeian $^{1}$ and Farzad Omidi Kashani* ${ }^{1 *}$ \\ ${ }^{1}$ Department of Orthopedic Surgery, Mashhad University of Medical Sciences, Mashhad, Iran
}

${ }^{2}$ Department of Radiology, Mashhad University of Medical Sciences, Mashhad, Iran

${ }^{3}$ Department of Community Medicine, Mashhad University of Medical Sciences, Mashhad, Iran

*Corresponding author: Farzad Omidi-Kashani, Orthopedic Department, Imam Reza Hospital, Imam Reza Square, Mashhad University of Medical Sciences, Mashhad, Iran, Tel: $9137913316 ;$ Email: omidif@mums.ac.ir

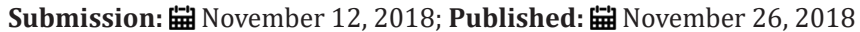

\begin{abstract}
Background: In the patients with chronic low back pain (CLBP), a variety of Magnetic Resonance Imaging (MRI) abnormalities may be present that may not be necessarily associated with clinical complaints. We aim to investigate the relationship between MRI findings of lumbar disc degeneration and Modic changes in the patients with CLBP.
\end{abstract}

Materials and Methods: We carried out a cross-sectional study on MRI scanning of 60 cases with CLBP. We used Pfirrmann classification and Modic changes (MC) for grading of lumbar disc degeneration and vertebral endplate signal changes, respectively. We studied these two indices in three lower lumbar intervertebral disc and adjacent endplates in cooperation with an expert radiologist and at the last, we analyzed and compared their relationships with each other.

Results: Our patients had equal sex distribution and mean age of 50.8 \pm 13.6 -year-old and Body Mass Index (BMI) of 27.3 \pm 4.7 . MC type II was the most common change throughout lumbar region. We found a positive effect of age on disc degeneration (not MC) in all three levels. In our study, BMI had no significant effect on these two indices. There was also significant correlation between these two indices in especially two lower lumbosacral spaces.

Conclusion: We found that age was a determinant factor for lumbar disc degeneration. A significant positive correlation was also found between disc degeneration and MC especially in two lower lumbosacral disc spaces. In other words, these two variables may in fact be a manifestation of a single degenerative process.

Keywords: Disc degeneration; Modic changes; Low back pain; Magnetic resonance imaging

\section{Introduction}

Low back pain is one of the most common causes of referral to a physician and at the same time is among the costliest health problems in developed societies [1]. Chronic low back pain (CLBP) is the most common cause of disability in people under the age of 45 years old, the third most common cause of surgery, and the fifth cause of hospitalization in developed countries like United States [2]. In 1986, about $\$ 20$ billion was spent on back pain in this country [3]. In the patients with refractory and CLBP, Magnetic Resonance Imaging (MRI) may be helpful in identifying underlying anatomy and illness, although many of MRI findings may not be necessarily related to clinical complaints [4,5]. Two of the most common MRI findings in these patients are Modic changes and degenerative disc disease (DDD). Although, these two indices occur in two distinct regions, both arise from degenerative process [6]. According to our knowledge, although there are numerous papers on these two degenerative indices (Modic changes and DDD), there is a few studies discussed the relationship between the two [7-10]. In this study, we paid attention to this matter to find a possible link between MRI findings of lumbar disc degeneration and Modic changes in the patients with CLBP.

\section{Materials and Methods}

After obtaining local institutional review board approval, we carried out a cross-sectional study on 60 cases with chronic low back pain (CLBP) lasted more than three months. Our inclusion criteria were age more than 20 years old, pain located between $12^{\text {th }}$ rib and transverse gluteal fold, and pain duration of more than three months. We excluded those cases with a history of trauma or surgery on lumbar spine, immature patients, patients with significant underlying diseases like autoimmune or malignant diseases, renal failure, immunosuppression, chronic infection, significant drug consumption, and magnetic resonance imaging 
(MRI) scanning older than two months. We used Pfirrmann classification for grading of lumbar disc degeneration on T2 weighted images of MRI [11]. According to this classification, disc degeneration was graded from I (normal disc with homogenous structure, clear distinction of nucleus and annulus, high signal intensity, and normal intervertebral height) to V (inhomogeneous black structure with no distinction of nucleus and annulus, decreased signal intensity, and collapsed height). For classifying vertebral endplate signal changes, we used the original paper published by Modic et al. [12]. In Modic type I, decreased signal intensity and increased signal intensity are observed along the adjacent vertebral endplates on $\mathrm{T} 1$ and $\mathrm{T} 2$ images, respectively. In Modic type II, increased signal intensity is present on both T1 and T2, while in Type III, decreased signal intensity exists on both images. These changes are assumed to be a result of fibrovascular, fatty, and bone sclerosis replacement, respectively [13]. We studied these two indices in three lower lumbar intervertebral disc and adjacent endplates in cooperation with an expert radiologist and at the last, we analyzed and compared their relationships with each other.

\section{Statistical analysis}

The descriptive statistics were expressed in terms of frequency, mean, standard deviation and appropriate tables and charts. We used Spearman correlation test to examine the correlation between variables and Chi-square or Fisher test to compare qualitative variables. To analyze the distribution of ordinal variables in two groups and more than two groups, Mann Whitney and Kruskalwallis tests were used, respectively. $\mathrm{P}$ value of $5 \%$ was considered significant statistically

\section{Results}

We studied 60 patients with equal sex distribution and with mean age of 50.8 \pm 13.6 -year-old and Body Mass Index (BMI) of 27.3 \pm 4.7 . Equal gender distribution was a completely incidental event. The main pathologic disease among our patients included lumbar spinal stenosis (38.3\%), lumbar disc herniation (33.3\%), spondylolisthesis (13.3\%), non-specific CLBP (11.7\%), and thoracic hyper-kyphosis (3.4\%). Prevalence of Modic changes (MC) were type I (3.3\%), type II (8.3\%), and type III (1.7\%). MC type II was the most common change throughout lumbar region, although in $87.7 \%$ of the patients, there was no evidence of any MC at all. The most common grade of disc degeneration among our patients in L3L4, L4-L5, and L5-S1 were grade 1 (31.7\%), grade 3 (33.3\%), and grade $3(41.7 \%)$, respectively.

Table 1 shows the association between age and BMI with MC and Disc degeneration. As the table shows, the only association we have found is the positive effect of age on disc degeneration in all three levels. This effect could not be found between these indices and Modic changes. Interestingly, BMI has no significant effect on Modic changes or disc degeneration. Table 2 shows the association between MC and grades of disc degeneration in three lower lumbar intervertebral discs. There is significant relationship between these two indices in L4-L5 and L5-S1 levels (P: 0.04 and 0.01, respectively), although a non-significant association also exists in L3-L4 level. This means that with increasing intensity of each of these two, the intensity of the other variable also increases.

Table 1: Association between age and BMI with Modic change and disc degeneration.

\begin{tabular}{|c|c|c|c|c|}
\hline \multirow{2}{*}{ Index/Lumbar Level } & \multicolumn{2}{|c|}{ Age } & \multicolumn{2}{|c|}{ BMI* } \\
\cline { 2 - 5 } & $\mathbf{r}$ & $\mathbf{p}$ & 0.59 & 0.65 \\
\hline L3-L4 & 0.08 & 0.53 & 0.086 & 0.513 \\
-Modic change & 0.451 & $<0.001$ & 0.05 & 0.67 \\
- Disc Degeneration & 0.03 & 0.76 & 0.114 & 0.387 \\
\hline L4-L5 & 0.541 & $<0.001$ & 0.08 & 0.52 \\
-Modic change & 0.05 & 0.67 & 0.039 & 0.766 \\
\hline - Disc Degeneration & 0.514 & 0.018 & & \\
\hline L5-S1 & & & & \\
- Disc Dedic change & & & & \\
\hline
\end{tabular}

*BMI: Body Mass Index

Table 2: Association between modic changes and disc degeneration.

\begin{tabular}{|c|c|c|c|c|c|c|c|}
\hline Grade of Degeneration/Level of Disc & $\begin{array}{c}\text { Grade I } \\
(\%)\end{array}$ & Grade II (\%) & $\begin{array}{c}\text { Grade III } \\
(\%)\end{array}$ & Grade IV (\%) & $\begin{array}{c}\text { Grade V } \\
(\%)\end{array}$ & Total (\%) & P value \\
\hline $\begin{array}{c}\text { L3-L4 } \\
\text {-Without Modic Change } \\
\text {-With Modic Change }\end{array}$ & $\begin{array}{r}18(34) \\
(14.3)\end{array}$ & $\begin{array}{l}17(32) \\
1(14.3)\end{array}$ & $\begin{array}{c}9(17) \\
2(28.6)\end{array}$ & $\begin{array}{c}4(7.5) \\
1(14.3)\end{array}$ & $\begin{array}{c}5(9.4) \\
2(28.6)\end{array}$ & $\begin{array}{l}53(100) \\
7(100)\end{array}$ & 0.08 \\
\hline
\end{tabular}




\begin{tabular}{|c|c|c|c|c|c|c|c|}
\hline $\begin{array}{c}\text { L4-L5 } \\
\text {-Without Modic Change } \\
\text {-With Modic Change }\end{array}$ & $\begin{array}{c}4(7.8) \\
0\end{array}$ & $\begin{array}{c}14(27.5) \\
0\end{array}$ & $\begin{array}{c}16(31.4) \\
4(44.4)\end{array}$ & $\begin{array}{c}13(25.5) \\
3(33.3)\end{array}$ & $\begin{array}{c}4(7.8) \\
2(22.2)\end{array}$ & $\begin{array}{l}51(100) \\
9(100)\end{array}$ & $0.04^{*}$ \\
\hline $\begin{array}{c}\text { L5-S1 } \\
\text {-Without Modic Change } \\
\text {-With Modic Change }\end{array}$ & $\begin{array}{c}5(8.3) \\
0\end{array}$ & $\begin{array}{c}14(25.9) \\
0\end{array}$ & $\begin{array}{c}23(42.6) \\
2(33.3)\end{array}$ & $\begin{array}{c}10(18.5) \\
2(33.3)\end{array}$ & $\begin{array}{c}2(3.7) \\
2(33.3)\end{array}$ & $\begin{array}{l}54(100) \\
6(100)\end{array}$ & $0.01^{*}$ \\
\hline
\end{tabular}

*Statistically significant

\section{Discussion}

$\mathrm{MC}$ and disc degeneration are subjects that have long been known and there are many articles have been exploring and discussing etiology, pathophysiology and determinant factors affecting their occurrence and severity, but few studies focused on the relationship between these two indices. Reviewing the literature suggests that higher BMI is associated with greater chance of endplate changes. In a study conducted in Finland, lumbosacral MRI scanning was performed on 228 workers to analyze MC and disc degeneration [14]. The authors found that although prevalence of MC and disc degeneration were similar, the main determinants for $\mathrm{MC}$ and disc degeneration were different. Age was associated with increase in both these degenerative changes but BMI and whole-body vibration were the main determinants of MC and disc degeneration, respectively. Another study on a mainly twin population also found a positive correlation between BMI and MC [15]. Our study could not show a significant effect of BMI on MC or disc degeneration. In our study, we could only find a positive effect of age on disc degeneration (not MC). These contradictions may be due to differences in sample size and individual characteristics of the patients being studied.

One of the studies that worked on MC and disc degeneration is related to Guo et al. [16] who retrospectively studied the correlation between MC and disc degeneration in lower lumbar area. Similar to our study, they evaluated lower three lumbar segments by MRI scanning. They found that type II MCs was the most common type that mostly situated in L4-L5 region. According to their study, MCs (particularly type II) have positive relationship with lumbar disc degeneration and therefore, could be assumed to be one of the indicators of lumbar disc degenerations. This study was in line with our study and had similar results. Another study that has similar results to ours is Teichtahl's that performed lumbosacral MRI in 72 cases unselected for LBP [17]. The results of this cross-sectional study indicated that lumbar disc degeneration is highly associated with MC and thus used the phrase "whole-organ pathology" for these two indices.

Xiao et al. [18] carried out a relatively large study on 345 patients. They performed MRI scanning of the lumbosacral region in order to assess possible relationship between MC and disc degeneration (by Pfirrmann grade). They identified a positive relationship between the two indices in such a way that MC can reflect the degree of disc degeneration and vice versa. In addition to this large study, we found a larger study also deals with the relationship between these two indices [8]. In this study, the authors performed clinical and para-clinical (lumbar spine MRI) assessment on 2,449 Chinese volunteers in order to investigate their possible associations.
According to our knowledge, this is the largest study on MC and disc degeneration. The authors found that overall incidence of MC was $5.8 \%$ that highly associated with aging. They found that aging, smoking, obesity, Schmorl node, degenerated disc, and a previous history of trauma were determinant factors for MC in lower lumbar area and these changes were highly associated with historical LBP (both in severity and symptom duration). If we put all the results of these studies with the results of our own research work, it seems that MC and disc degeneration are two aging indices have a positive relationship with each other and have relatively similar determinants.

Our study had some important weaknesses and strengths. First, the sample size of our study was relatively fewer than that of the similar studies. This flaw certainly leads to reduce the precision of the statistical tests and finally the power of conclusion. Second, the study was conducted at a clinic in a public (not private) hospital. Therefore, the sample tested may not be an appropriate sample for assessing the entire community. But, a great benefit of this study was the presence of an experienced radiologist at the heart of the research team, which has greatly contributed to the increased readability of the study. In conclusion, we found that age was a determinant for lumbar disc degeneration. A significant positive correlation was also found between disc degeneration and MC especially in two lower lumbosacral disc spaces. In other words, these two variables may in fact be a manifestation of a single degenerative process.

\section{Acknowledgement}

The authors thank the respected staff of the Parsian Imaging Department for their cooperation in this project. Approval code issued by the institutional review board (IRB) and the name of the institution(s) that granted the approval: Approval Code: 950485 and code of Ethics Committee: IR.MUMS.fm.REC.1395.447, Mashhad University of Medical Sciences, Mashhad, Iran.

The authors thank Student Research Committee, Faculty of Medicine, Mashhad University of Medical Sciences for financial support. This paper is based on a medical student's thesis pertaining to Zahra Hasani (record No: 950485).

\section{References}

1. Casazza BA (2012) Diagnosis and treatment of acute low back pain. Am Fam Physician 85(4): 343-350.

2. Basaran A, Topatan S (2008) Spinal balloon nucleoplasty: A hypothetical minimally invasive treatment for herniated nucleus pulposus. Med Hypotheses 70(6): 1201-1206.

3. Dieleman JL, Baral R, Birger M, Bui AL, Bulchis A, et al. (2016) US spending on personal health care and public health, 1996-2013. JAMA 316(24): 2627-2646. 
4. Babińska A, Wawrzynek W, Skupiński J, Kasprowska S, Piechota M, et al (2018) Patient with spine pain and magnetic resonance imaging result. Wiad Lek 71(2 pt 2): 389-397.

5. Kohat AK, Kalita J, Ramanivas S, Misra UK, Phadke RV (2017) Clinical significance of magnetic resonance imaging findings in chronic low backache. Indian J Med Res 145(6): 796-803.

6. Luoma K, Vehmas T, Kerttula L, Grönblad M, Rinne E (2016) Chronic low back pain in relation to Modic changes, bony endplate lesions, and disc degeneration in a prospective MRI study. Eur Spine J 25(9): 2873-2881.

7. Määttä JH, MacGregor A, Karppinen J, Williams FM (2016) The relationship between Modic changes and intervertebral disc degeneration. BMC Musculoskelet Disord 17: 371.

8. Mok FP, Samartzis D, Karppinen J, Fong DY, Luk KD, et al. (2016) Modic changes of the lumbar spine: Prevalence, risk factors, and association with disc degeneration and low back pain in a large-scale population-based cohort. Spine J 16(1): 32-41.

9. Hu ZJ, Zhao FD, Fang XQ, Fan SW (2009) Modic changes, possible causes and promotion to lumbar intervertebral disc degeneration. Med Hypotheses 73(6): 930-932.

10. Luoma K, Vehmas T, Grönblad M, Kerttula L, Kääpä E (2009) Relationship of modic type 1 change with disc degeneration: A prospective MRI study. Skeletal Radiol 38(3): 237-244.

11. Pfirrmann CW, Metzdorf A, Zanetti M, Hodler J, Boos N (2001) Magnetic resonance classification of lumbar intervertebral disc degeneration. Spine 26(17): 1873-1888.
12. Modic MT, Steinberg PM, Ross JS, Masaryk TJ, Carter JR (1988) Degenerative disc disease: Assessment of changes in vertebral body marrow with MR imaging. Radiology 166(1 Pt 1): 193-199.

13. Hutton MJ, Bayer JH, Powell JM (2011) Modic vertebral body changes: The natural history as assessed by consecutive magnetic resonance imaging. Spine 36(26): 2304-2307.

14. Kuisma M, Karppinen J, Haapea M, Niinimäki J, Ojala R, et al. (2008) Are the determinants of vertebral endplate changes and severe disc degeneration in the lumbar spine the same? A magnetic resonance imaging study in middle-aged male workers. BMC Musculoskelet Disord 9: 51.

15. Määttä JH, Wadge S, MacGregor A, Karppinen J, Williams FM (2015) ISSLS prize winner: Vertebral endplate (modic) change is an independent risk factor for episodes of severe and disabling low back pain. Spine (Phila Pa 1976) 40(15): 1187-1193.

16. Guo R, Yang X, Zhong Y, Lai Q Gao T, et al. (2018) Correlations between Modic change and degeneration in 3-joint complex of the lower lumbar spine: A retrospective study. Medicine (Baltimore) 97(38): e12496.

17. Teichtahl AJ, Urquhart DM, Wang Y, Wluka AE, Sullivan OR, et al. (2016) Lumbar disc degeneration is associated with modic change and high paraspinal fat content-a 3.0T magnetic resonance imaging study. BMC Musculoskelet Disord 17(1): 439.

18. Xiao L, Ni C, Shi J, Wang Z, Wang S, et al. (2017) Analysis of correlation between vertebral endplate change and lumbar disc degeneration. Med Sci Monit 23: 4932-4938.
Creative Commons Attribution 4.0 International License

For possible submissions Click Here

\section{Submit Article}

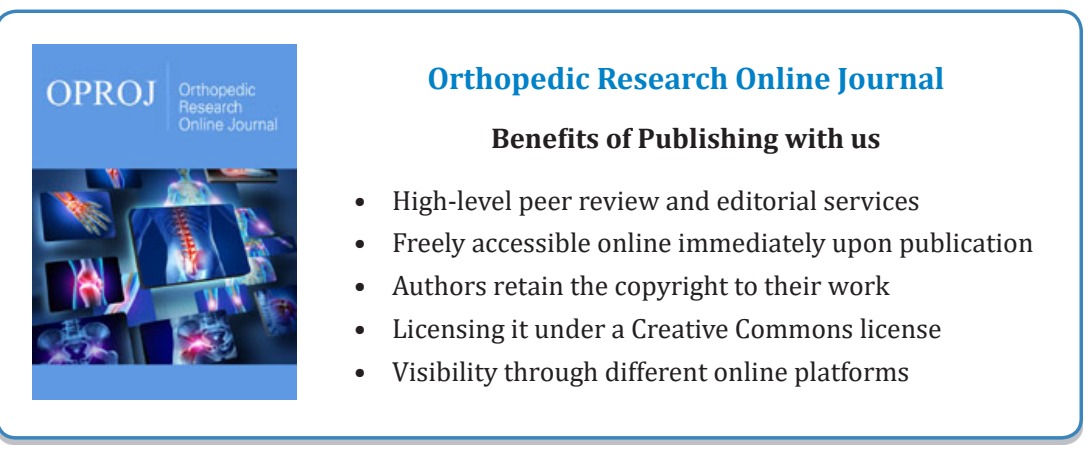

